\title{
Comorbidities and co-medications in populations with and without chronic hepatitis $C$ virus infection in Japan between 2015 and 2016
}

Daniel J. Ruzicka ${ }^{1 *}$, Jumpei Tetsuka ${ }^{1}$, Go Fujimoto ${ }^{2}$ and Tatsuya Kanto ${ }^{3}$

\begin{abstract}
Background: Direct-acting anti-viral agents have improved the treatment of chronic hepatitis $\mathrm{C}$ virus $(\mathrm{HCV})$ infection, but this treatment is challenging for patients using co-medications because of potential drug-drug interactions. This study aimed to examine the comorbidities and co-medications of Japanese chronic HCV patients by age group, compared with a non-HCV patient population.

Methods: This was a retrospective observational study using a hospital-based medical claims database. We extracted data of patients with chronic HCV aged $\geq 18$ years, and age-, sex-, and hospital-matched patients without HCV, for the period from January 2015 to November 2016, and then examined chronic comorbidities, long-term co-medications, and medications prescribed at least once during the study period.

Results: We analysed data from 128,967 chronic HCV patients and 515,868 non-HCV patients. The median age was 70 years, and $51.0 \%$ of patients were male. More chronic HCV patients than non-HCV patients (70.5\% vs. $47.1 \%)$ had at least one comorbidity, and older patients had more comorbidities than younger patients. The most common comorbidities in chronic HCV patients were diseases of oesophagus, stomach and duodenum (41.7\%), followed by hypertensive diseases (31.4\%). Chronic HCV patients used co-medications more commonly than non-HCV patients, and older patients used more co-medications. The most common long-term co-medications in chronic HCV patients were proton pump inhibitors (14.0\%), which were prescribed to 31.9\% of chronic HCV patients at least once during the study period.

Conclusions: Patients with chronic HCV in Japan had more comorbidities than patients without chronic HCV regardless of age. Particularly older patients, who constitute the majority of the HCV patient population in Japan, commonly had multiple comorbidities and used co-medications. To optimise HCV treatment, physicians need to know the exact medication profiles of patients and take appropriate action to manage drug-drug interactions.
\end{abstract}

Keywords: Chronic hepatitis C, Comorbidity, Drug interactions, Japan, Polypharmacy

\footnotetext{
* Correspondence: daniel.ruzicka@merck.com

${ }^{1}$ Medical Affairs, MSD K.K, Kitanomaru Square, 1-13-12 Kudan-kita, Chiyoda-ku,

Tokyo 102-8667, Japan

Full list of author information is available at the end of the article
}

(c) The Author(s). 2018 Open Access This article is distributed under the terms of the Creative Commons Attribution 4.0 International License (http://creativecommons.org/licenses/by/4.0/), which permits unrestricted use, distribution, and reproduction in any medium, provided you give appropriate credit to the original author(s) and the source, provide a link to the Creative Commons license, and indicate if changes were made. The Creative Commons Public Domain Dedication waiver (http://creativecommons.org/publicdomain/zero/1.0/) applies to the data made available in this article, unless otherwise stated. 


\section{Background}

The advent of direct-acting anti-viral agents (DAAs) has dramatically improved the treatment of hepatitis $C$ virus (HCV) infection. Treatment with these agents can achieve high sustained virologic response rates with a favourable tolerability and shortened treatment duration $[1,2]$. However, DAA treatment is challenging for patients who use co-medications, especially drugs metabolised by cytochrome P450 CYP3A4, because of potential drug-drug interactions (DDIs) [3].

Chronic HCV infection causes persistent inflammation, which can result in the development of both liver diseases (e.g. cirrhosis, hepatocellular carcinoma) and extrahepatic diseases [4, 5]. Chronic HCV patients therefore tend to have various comorbidities. Some comorbidities such as HIV or hepatitis B virus (HBV) co-infection, obesity, and insulin resistance can contribute to the progression of liver fibrosis, which can lead to advanced liver diseases [6, 7]. Moreover, it has been reported that chronic $\mathrm{HCV}$ patients also have an increased risk of death from extrahepatic diseases such as circulatory diseases, renal diseases, and non-liver cancers compared with non-HCV patients [8]. Thus, management of these comorbidities is important to prevent disease progression and reduce mortality from both liver diseases and extrahepatic diseases. However, the use of co-medication to treat comorbidities, regardless of whether it is long- or short-term, can complicate HCV treatment because of the risk of DDIs with DAAs [3,9]. The situation is even more challenging when treating older patients because they tend to have more comorbidities and use more co-medications [10].

Physicians therefore need to understand the comorbidities and co-medication profiles of chronic $\mathrm{HCV}$ patients to appropriately manage chronic HCV infection along with their comorbidities. In the US, studies have examined the comorbidities and co-medications of chronic HCV patients $[9,11]$. However, to our knowledge, no such studies have been conducted in Japan, although the profile of chronic $\mathrm{HCV}$ patients there may differ from elsewhere. In Japan, the prevalence of HCV infection is higher in older people $[12,13]$. HCV started to spread in the 1930s through intravenous drug abuse or medical procedures such as blood transfusion and the use of contaminated needles. However, transmission through blood transfusion has dramatically decreased over the past 50 years thanks to the discovery of $\mathrm{HCV}$ and the introduction of $\mathrm{HCV}$ antibody screening of donor blood [14], resulting in a low prevalence of HCV infection among younger people [15]. Because of the age distribution of the patient population and potential international differences in treatment patterns, it is important to obtain real-world data about comorbidities and co-medications in chronic HCV patients in Japan.
The aim of this study was therefore to describe the prevalence of comorbidities and the use of co-medications in chronic $\mathrm{HCV}$ patients in Japan by age group, compared with an age-, sex-, and hospital-matched non-HCV patient population, using a large-scale medical claims database. This study will create new data that are not yet available in Japan, which will provide physicians with the better understanding of chronic HCV patients in Japan.

\section{Methods}

\section{Study design and data source}

This was a retrospective, observational database study to examine the number and types of comorbidities and co-medications by age group in patients with and those without chronic HCV. Data were extracted from a hospital-based medical claims database in Japan, which was constructed by Medical Data Vision Co., Ltd. As of January 2017, the database contained data on over 17 million patients in 288 hospitals in Japan, all of which are hospitals with advanced medical care capabilities (e.g., acute care hospitals, general hospitals) and use the diagnosis procedure combination/per-diem payment system. Of these hospitals, 176 (61.1\%) had 200-499 beds, 59 (20.5\%) had fewer than 200 beds, and 53 (18.4\%) had 500 beds or more. The database contained both inpatient and outpatient claims data from any department of the hospitals, including age, sex, diagnoses, medical procedures, prescriptions (inpatient/outpatient prescription, claim name and code, dose, prescription days), and hospitalisation details (if any). Because this hospital-based claims database was not linked to patients' medical records, any medical and treatment histories recorded at different hospitals could not be traced.

\section{Study population}

We extracted data on patients aged $\geq 18$ years with at least one record of chronic HCV (the International Statistical Classification of Diseases and Related Health Problems 10th Revision [ICD-10] code: B18.2) between January 2015 and November 2016 (the study period). As non-HCV controls, we extracted data of patients who had no record of chronic HCV (B18.2) during the study period, who were matched to chronic $\mathrm{HCV}$ patients according to age (age group), sex, and hospital. The matching ratio of chronic $\mathrm{HCV}$ patients to non-HCV controls was 1:10. Patient age was calculated in the month of the first record during the study period, and patients were grouped into the following age ranges: $18-$ 24, 25-29, 30-34, 35-39, 40-44, 45-49, 50-54, 55-59, $60-64,65-69,70-74,75-79,80-84,85-89$, and $\geq$ 90 years.

Chronic HCV patients who had prescription records of either DAAs or peginterferon plus ribavirin were defined as treated. The type of HCV treatment was defined 
as either DAAs or peginterferon plus ribavirin depending on the patients' latest record of HCV treatment. Patients who had no record of DAAs or peginterferon plus ribavirin combination therapy during the study period were considered to be untreated.

\section{Definitions of comorbidities and co-medications Comorbidities}

A comorbidity was identified using ICD-10 codes and defined as another disease (i.e. excluding chronic HCV [B18.2] and chronic hepatitis [K73]) recorded over a time frame of 6 months or more during the study period. If the time from the first to the last record of a particular disease was 6 months or more, the disease was treated as a comorbidity. The minimum time frame of 6 months was set to target chronic diseases from a clinical viewpoint. Comorbidities were classified using the ICD-10 three-character code block categories (e.g. A00-A09 for intestinal infectious diseases) [16].

Among comorbidities, the ten relevant systemic diseases of interest were defined as follows: metabolic disorders (E70-E90); diabetes mellitus (E10-E14); cardiovascular diseases (ischaemic heart diseases [I20-I25], heart failure [150], and cerebrovascular diseases [160-I69]); hypertensive diseases (I10-I15); renal failure (N17N19); dermatitis and eczema (L20-L30); diseases of oesophagus, stomach and duodenum (K20-K31); liver cancers (C22); neoplasms other than liver cancers (C00-D49 except for C22); and psychiatric disorders (mental and behavioural disorders [F00-F99] and sleep disorders [G47]).

\section{Co-medications}

Medications were classified using the fourth level of the EphMRA Anatomical classification system codes (ATC codes) [17]. A non-HCV-related medication was considered to be a co-medication if 1) it was supplied for a total of $\geq 180$ days or 2) the ATC code was recorded in 6 or more consecutive months during the study period. DAAs, ribavirin, peginterferon, ursodeoxycholic acid, and monoammonium glycyrrhizinate/glycine/L-Cysteine hydrochloride hydrate were considered to be HCV-related medications, and not co-medications.

We targeted co-medications used for a long period. The total of 180 prescription days was a strict requirement because the study period was about 2 years. However, because patients need to visit the same hospital at least twice to receive medications to cover 180 days, we considered that the co-medications identified could probably be those used for the treatment of each patient's chronic comorbid conditions.

Although we focused on long-term co-medications, we also examined the use of non-HCV-related medications prescribed at least once during the study period because even one-off or short-term use of a medication can influence the patient's treatment regimen. As with co-medications, non-HCV-related medications prescribed at least once during the study period were classified using the fourth level of ATC codes. Examining medications used for a short period will shed light on the types of medications commonly used in Japanese chronic HCV patients, which might otherwise be underestimated using our strict definition of co-medications.

\section{Statistical analysis}

The patients' demographic and clinical characteristics were summarised descriptively for chronic $\mathrm{HCV}$ patients and non-HCV patients; these included age; sex; hospitalisation (the number of patients with hospital admission, the total length and number of hospital admissions); mental behavioural disorders due to use of alcohol (ICD-10 code F10), tobacco (F17), psychoactive substances (F12-16, F18-19), or opioids (F11); HIV co-infection (B20-24); and HBV co-infection (B18.0, B18.1). Disease names coded as chronic HCV (B18.2) and types of $\mathrm{HCV}$ treatment were summarised descriptively for chronic $\mathrm{HCV}$ patients.

Different types of comorbidities were summarised descriptively for each group. To compare the prevalence of different types of comorbidities in chronic $\mathrm{HCV}$ and non-HCV patients, the chi-square test was performed. The number of comorbidities by patient was summarised by age group for each patient group. Co-medications and non-HCV-related medications prescribed at least once during the study period were summarised descriptively by age group for each patient group, as was the number of co-medications by patient.

All statistical analyses were performed using SAS release 9.4 (SAS Institute Inc., Cary, NC, USA).

\section{Results}

\section{Patient characteristics}

We analysed data from 128,967 chronic HCV patients and 515,868 non-HCV patients (Table 1). The median age was 70 years and $70 \%$ of patients were aged between 60 and 84 years; $51.0 \%$ of patients were male. Patients with a record of hospital admission during the study period accounted for $43.0 \%$ of chronic $\mathrm{HCV}$ patients and $27.5 \%$ of non-HCV patients. In the chronic $\mathrm{HCV}$ group, 11,533 (8.9\%) patients had HCV-related cirrhosis, and 17,244 (13.4\%) patients were treated. Of these, 16,338 (94.7\%) patients received DAAs and 906 (5.3\%) received peginterferon plus ribavirin.

\section{Comorbidities}

Overall, $70.5 \%$ of chronic HCV patients and $47.1 \%$ of non-HCV patients had at least one comorbidity. Proportions of patients with $1-3,4-6$, and $\geq 7$ comorbidities 
Table 1 Demographic characteristics of chronic HCV patients and non-HCV patients

\begin{tabular}{|c|c|c|c|c|}
\hline & \multicolumn{2}{|c|}{$\begin{array}{l}\text { Chronic HCV patients } \\
(n=128,967)\end{array}$} & \multicolumn{2}{|c|}{$\begin{array}{l}\text { Non-HCV patients } \\
(n=515,868)\end{array}$} \\
\hline & $\mathrm{n}$ & (\%) & $n$ & $(\%)$ \\
\hline Male & 65,781 & $(51.0)$ & 263,124 & $(51.0)$ \\
\hline $\begin{array}{l}\text { Age (years), median } \\
\text { (range) }\end{array}$ & 70 & $(18-107)$ & 70 & $(18-109)$ \\
\hline \multicolumn{5}{|l|}{ Age category (years) } \\
\hline $18-24$ & 556 & $(0.4)$ & 2224 & $(0.4)$ \\
\hline $25-29$ & 779 & $(0.6)$ & 3116 & $(0.6)$ \\
\hline $30-34$ & 1388 & (1.1) & 5552 & $(1.1)$ \\
\hline $35-39$ & 2095 & (1.6) & 8380 & (1.6) \\
\hline $40-44$ & 3252 & $(2.5)$ & 13,008 & $(2.5)$ \\
\hline $45-49$ & 4639 & (3.6) & 18,556 & (3.6) \\
\hline $50-54$ & 7008 & $(5.4)$ & 28,032 & (5.4) \\
\hline $55-59$ & 9221 & (7.1) & 36,884 & $(7.1)$ \\
\hline $60-64$ & 13,581 & $(10.5)$ & 54,324 & $(10.5)$ \\
\hline $65-69$ & 19,222 & $(14.9)$ & 76,888 & $(14.9)$ \\
\hline $70-74$ & 20,376 & $(15.8)$ & 81,504 & $(15.8)$ \\
\hline $75-79$ & 20,279 & $(15.7)$ & 81,116 & $(15.7)$ \\
\hline $80-84$ & 16,881 & $(13.1)$ & 67,524 & $(13.1)$ \\
\hline $85-89$ & 7525 & $(5.8)$ & 30,100 & $(5.8)$ \\
\hline$\geq 90$ & 2165 & $(1.7)$ & 8660 & $(1.7)$ \\
\hline \multicolumn{5}{|l|}{ Chronic HCV disease ${ }^{a}$} \\
\hline Chronic hepatitis C & 85,282 & $(66.1)$ & & - \\
\hline Hepatitis C & 42,802 & $(33.2)$ & & - \\
\hline HCV-related cirrhosis & 11,533 & (8.9) & & - \\
\hline Hepatitis C virus infection & 2560 & $(2.0)$ & & - \\
\hline $\begin{array}{l}\text { Decompensated } \\
\text { HCV-related cirrhosis }\end{array}$ & 645 & $(0.5)$ & & - \\
\hline $\begin{array}{l}\text { Compensated } \\
\text { HCV-related cirrhosis }\end{array}$ & 434 & $(0.3)$ & & - \\
\hline With treatment of HCV & 17,244 & $(13.4)$ & & - \\
\hline DAA & 16,338 & $(94.7)$ & & - \\
\hline Peginterferon + ribavirin & 906 & (5.3) & & - \\
\hline \multicolumn{5}{|l|}{$\begin{array}{l}\text { Mental and behavioural } \\
\text { disorders due to }\end{array}$} \\
\hline Alcohol & 515 & $(0.4)$ & 1114 & $(0.2)$ \\
\hline Tobacco & 345 & $(0.3)$ & 607 & $(0.1)$ \\
\hline $\begin{array}{l}\text { Psychoactive } \\
\text { substance use }\end{array}$ & 137 & $(0.1)$ & 135 & $(0.0)$ \\
\hline Opioid use & 0 & $(0.0)$ & 0 & $(0.0)$ \\
\hline \multicolumn{5}{|l|}{ Co-infection ${ }^{b}$} \\
\hline HIV & 336 & $(0.3)$ & 167 & $(0.0)$ \\
\hline HBV & 5368 & $(4.2)$ & 4823 & $(0.9)$ \\
\hline Hospital admission ${ }^{c}$ & 55,423 & $(43.0)$ & 141,817 & $(27.5)$ \\
\hline
\end{tabular}

Table 1 Demographic characteristics of chronic HCV patients and non-HCV patients (Continued)

\begin{tabular}{|c|c|c|c|c|}
\hline & \multicolumn{2}{|c|}{$\begin{array}{l}\text { Chronic HCV patients } \\
(n=128,967)\end{array}$} & \multicolumn{2}{|c|}{$\begin{array}{l}\text { Non-HCV patients } \\
(n=515,868)\end{array}$} \\
\hline & $\mathrm{n}$ & $(\%)$ & $\mathrm{n}$ & (\%) \\
\hline $\begin{array}{l}\text { Total length of hospital } \\
\text { admissions (days), } \\
\text { median (range) }\end{array}$ & 18 & $(1-678)$ & 13 & $(1-684)$ \\
\hline \multicolumn{5}{|l|}{$\begin{array}{l}\text { Total number of } \\
\text { hospital admissions }\end{array}$} \\
\hline Once & 32,492 & $(25.2)$ & 100,483 & (19.5) \\
\hline Twice or more & 22,931 & (17.8) & 41,334 & (8.0) \\
\hline
\end{tabular}

Notes: HCV, hepatitis C virus; DAA, direct-acting antiviral agent; HBV, hepatitis $B$ virus

${ }^{\text {a }}$ For diseases coded as chronic HCV (B18.2), the number and proportion of patients with that specific disease were shown

${ }^{b}$ For the following diseases, the number and proportion of patients with at least one disease record during the study period were shown: mental and behavioural disorders due to use of alcohol (F10); tobacco (F17); psychoactive substances (F12-16, F18-19); opioids (F11), HIV (B20-24), and HBV (B18.0, B18.1)

'All-cause hospital admissions during the study period were counted

were $17.9,15.9$, and $36.7 \%$ in chronic $\mathrm{HCV}$ patients, and $17.6,12.2$, and $17.3 \%$ in non-HCV patients. Figure 1 shows the number of comorbidities by age group. In all age groups, the proportion of patients with at least one comorbidity was larger in chronic $\mathrm{HCV}$ patients than that in non-HCV patients. Patients in the older age groups tended to have more comorbidities than patients in the younger age groups, and $44.9 \%$ of chronic HCV patients aged $75-79$ years had $\geq 7$ comorbidities. In those aged 80 years or older, however, the proportions of patients with at least one comorbidity decreased.

The 20 most common comorbidities in chronic HCV patients are listed in Table 2. Diseases of oesophagus, stomach and duodenum were the most common (41.7\%), followed by hypertensive diseases $(31.4 \%)$ and metabolic disorders (28.2\%). Aside from liver diseases, malignant neoplasms of digestive organs and gallbladder/biliary tract/pancreas disorders were much more prevalent in chronic $\mathrm{HCV}$ patients than in non-HCV patients $(15.0 \%$ vs 4.6 and $11.2 \%$ vs $2.9 \%)$.

The prevalence of each type of relevant systemic diseases was higher in chronic HCV patients than that in non-HCV patients (Table 2). Neoplasms other than liver cancers were common in both groups, and present in $20.4 \%$ of chronic $\mathrm{HCV}$ patients and $15.3 \%$ of non-HCV patients. Only $4.0 \%$ of chronic $\mathrm{HCV}$ patients had renal failure.

The prevalence of each systemic disease by age group is shown in Fig. 2. Diseases of oesophagus, stomach and duodenum were present in over $10 \%$ of chronic $\mathrm{HCV}$ patients, even in the youngest age group. Diabetes was more prevalent in chronic HCV patients aged between 60 and 79 years: about $30 \%$ vs. under $15 \%$ in non- $\mathrm{HCV}$ 


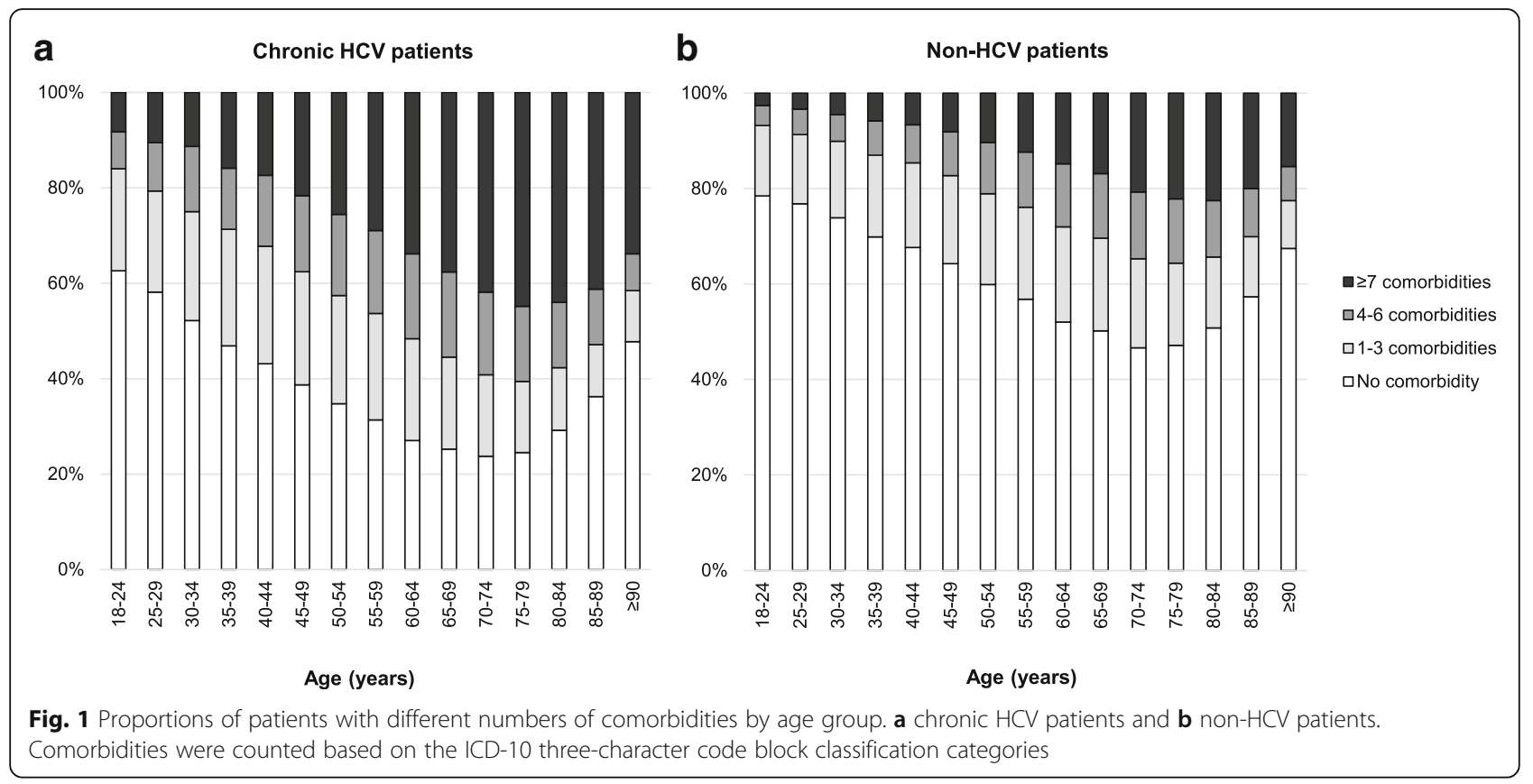

patients. Psychiatric disorders were common in chronic HCV patients aged 45 years or older, with a prevalence of approximately $20-25 \%$. The prevalence of cardiovascular diseases was low in the younger age groups in both groups, but increased in older chronic $\mathrm{HCV}$ patients with a peak of $29.2 \%$ in the $85-89$ year group. Although the prevalence of neoplasms other than liver cancers was similar in both groups in patients aged $<60$ years, its prevalence exceeded $20 \%$ in chronic $\mathrm{HCV}$ patients aged $65-69$ years and reached $25.2 \%$ in the $75-79$ year group, in comparison to a peak prevalence of $18.4 \%$ in non-HCV patients aged $70-74$ years.

\section{Co-medications}

Overall, $41.9 \%$ of chronic HCV patients and $26.0 \%$ of non-HCV patients used at least one co-medication supplied for $\geq 180$ days or recorded in at least 6 consecutive months. Of chronic $\mathrm{HCV}$ patients, $19.0 \%$ used 1-3 co-medications, $11.0 \%$ used $4-6$, and $11.9 \%$ used $\geq 7$ co-medications, compared with $13.8,6.5$, and $5.8 \%$ of non-HCV patients. Figure 3 shows the number of co-medications by age group. In all age groups, the proportion of patients with at least one co-medication was larger among chronic $\mathrm{HCV}$ patients. Patients in the older age groups tended to use more co-medications than patients in the younger age groups, and $16.2 \%$ of chronic HCV patients aged $80-84$ years used $\geq 7$ co-medications.

The most common co-medications in chronic $\mathrm{HCV}$ patients were proton pump inhibitors (14.0\%), calcium antagonists (12.5\%), and angiotensin-II antagonists (9.0\%) (Table 3). Additional separate analysis of treated and non-treated chronic $\mathrm{HCV}$ patients revealed no major difference between these groups (Additional file 1: Table S1). Almost twice as many chronic HCV patients as non-HCV patients used these co-medications. In both groups, $5.8 \%$ of patients used statins as co-medications. Most common co-medications were used more by older patients. For example, proton pump inhibitors or calcium antagonists were used by over $15 \%$ of chronic HCV patients aged 75 years or over but by fewer than $5 \%$ of patients aged $18-44$ years.

In addition to co-medications, we also examined the non-HCV-related medications prescribed at least once during the study period to identify which medications are commonly used by chronic HCV patients. Table 3 shows the medications prescribed in $\geq 20 \%$ of chronic $\mathrm{HCV}$ patients (excluding medications classified as hospital solutions or diagnostic agents). Over 30\% of chronic HCV patients aged $\geq 65$ years used proton pump inhibitors or antacids, both of which were also common co-medications. These medications were used more commonly by chronic $\mathrm{HCV}$ patients compared with non-HCV patients (proton pump inhibitors, 31.9 and 17.4\%; antacids, 28.8 and $15.8 \%$, respectively). Anti-rheumatics were prescribed to approximately $28 \%$ of chronic $\mathrm{HCV}$ patients across all age groups.

\section{Discussion}

To our knowledge, this is the first study to examine comorbidities and co-medications in chronic $\mathrm{HCV}$ patients in Japan. We found that chronic HCV patients had more comorbidities and used more co-medications than non-HCV patients. Older chronic HCV patients, who 
Table 2 The 20 most common comorbidities in chronic HCV patients and prevalence of relevant systemic diseases

\begin{tabular}{|c|c|c|c|c|c|}
\hline \multirow[b]{2}{*}{ Type of comorbidities/relevant systemic diseases } & \multirow[b]{2}{*}{ ICD-10 code blocks } & \multicolumn{2}{|c|}{$\begin{array}{l}\text { Chronic HCV patients } \\
(n=128,967)\end{array}$} & \multicolumn{2}{|c|}{$\begin{array}{l}\text { Non-HCV patients } \\
(n=515,868)\end{array}$} \\
\hline & & $n$ & $\%$ & $n$ & $\%$ \\
\hline \multicolumn{6}{|l|}{ The 20 most common comorbidities } \\
\hline Diseases of oesophagus, stomach and duodenum ${ }^{\#}$ & K20-K31 & 53,817 & 41.7 & 94,325 & 18.3 \\
\hline Hypertensive diseases $\#$ & $\mid 10-115$ & 40,466 & 31.4 & 79,602 & 15.4 \\
\hline Metabolic disorders $\#$ & E70-E90 & 36,403 & 28.2 & 71,959 & 13.9 \\
\hline Diabetes mellitus \# & E10-E14 & 33,632 & 26.1 & 60,428 & 11.7 \\
\hline Other diseases of intestines & K55-K64 & 31,581 & 24.5 & 61,083 & 11.8 \\
\hline Episodic and paroxysmal disorders & G40-G47 & 25,077 & 19.4 & 44,756 & 8.7 \\
\hline Other dorsopathies & M50-M54 & 22,629 & 17.5 & 39,653 & 7.7 \\
\hline Diseases of liver & K70-K77 & 22,080 & 17.1 & 20,432 & 4.0 \\
\hline Malignant neoplasms of digestive organs & $\mathrm{C} 15-\mathrm{C} 26$ & 19,405 & 15.0 & 23,518 & 4.6 \\
\hline Other forms of heart disease & $130-152$ & 18,715 & 14.5 & 44,546 & 8.6 \\
\hline Dermatitis and eczema ${ }^{\#}$ & L20-L30 & 16,294 & 12.6 & 24,107 & 4.7 \\
\hline Nutritional anaemias & D50-D53 & 15,433 & 12.0 & 20,678 & 4.0 \\
\hline Disorders of gallbladder, biliary tract and pancreas & K80-K87 & 14,471 & 11.2 & 14,977 & 2.9 \\
\hline General symptoms and signs & R50-R69 & 13,548 & 10.5 & 22,990 & 4.5 \\
\hline Ischaemic heart diseases & $120-125$ & 12,355 & 9.6 & 31,462 & 6.1 \\
\hline Chronic lower respiratory diseases & J40-J47 & 11,400 & 8.8 & 23,630 & 4.6 \\
\hline Disorders of bone density and structure & M80-M85 & 10,203 & 7.9 & 23,124 & 4.5 \\
\hline Other diseases of upper respiratory tract & J30-J39 & 10,168 & 7.9 & 20,404 & 4.0 \\
\hline $\begin{array}{l}\text { Disorders of ocular muscles, binocular movement, } \\
\text { accommodation and refraction }\end{array}$ & $\mathrm{H} 49-\mathrm{H} 52$ & 9941 & 7.7 & 30,291 & 5.9 \\
\hline Cerebrovascular diseases & $160-169$ & 9914 & 7.7 & 28,193 & 5.5 \\
\hline \multicolumn{6}{|l|}{ Relevant systemic diseases ${ }^{\mathrm{a}}$} \\
\hline Psychiatric disorders & $-{ }^{\mathrm{b}}$ & 28,253 & 21.9 & 51,813 & 10.0 \\
\hline Neoplasms other than liver cancers & $-{ }^{\mathrm{b}}$ & 26,286 & 20.4 & 79,126 & 15.3 \\
\hline Cardiovascular diseases & $-{ }^{b}$ & 24,000 & 18.6 & 62,901 & 12.2 \\
\hline Liver cancers & $-{ }^{b}$ & 11,878 & 9.2 & 1578 & 0.3 \\
\hline Renal failure & $-\mathrm{b}$ & 5180 & 4.0 & 9293 & 1.8 \\
\hline
\end{tabular}

$P$-values for the comparisons of the percentages in chronic HCV patients and non-HCV patients using the chi-square test were all $<0.0001$

${ }^{a}$ Among the ten relevant systemic diseases of interest, five diseases that were not defined using ICD-10 three-character code block categories are listed under this heading. The other five diseases are listed in the ranking of the 20 most common comorbidities and indicated by a sharp ( $)$

${ }^{b}$ These five relevant systemic diseases were defined as follows: psychiatric disorders included mental and behavioural disorders (F00-F99) and sleep disorders (G47). Neoplasms other than liver cancers were defined as C00-D49 except for C22. Cardiovascular diseases included ischaemic heart diseases (I20-I25), heart failure (150), and cerebrovascular diseases (160-169). Liver cancers were defined as C22. Renal failure were defined as N17-N19

constitute the majority of the $\mathrm{HCV}$ patient population in Japan, commonly had multiple comorbidities and used more co-medications, suggesting the difficulty of appropriate management of this patient population.

In this study, older chronic HCV patients were more likely than younger patients to have comorbidities. Interestingly, however, the proportion of patients with comorbidities decreased in patients aged $\geq 75$ years. This may be because those with fewer comorbidities tended to survive longer. It is also noteworthy that $16.0 \%$ of chronic HCV patients aged 18-24 years had four or more comorbidities, showing the relatively common presence of multiple comorbidities in young patients. Given that intravenous drug abuse is an important route of HCV transmission among young people [15], some of these young patients may be injecting drug users and are therefore more vulnerable to developing other diseases. However, these details could not be investigated in this study because of an absence of relevant data within the database.

The patterns of comorbidity distribution among chronic $\mathrm{HCV}$ patients were comparable to those of non-HCV patients who were 30 years older. The percentage of patients with no comorbidities decreased 


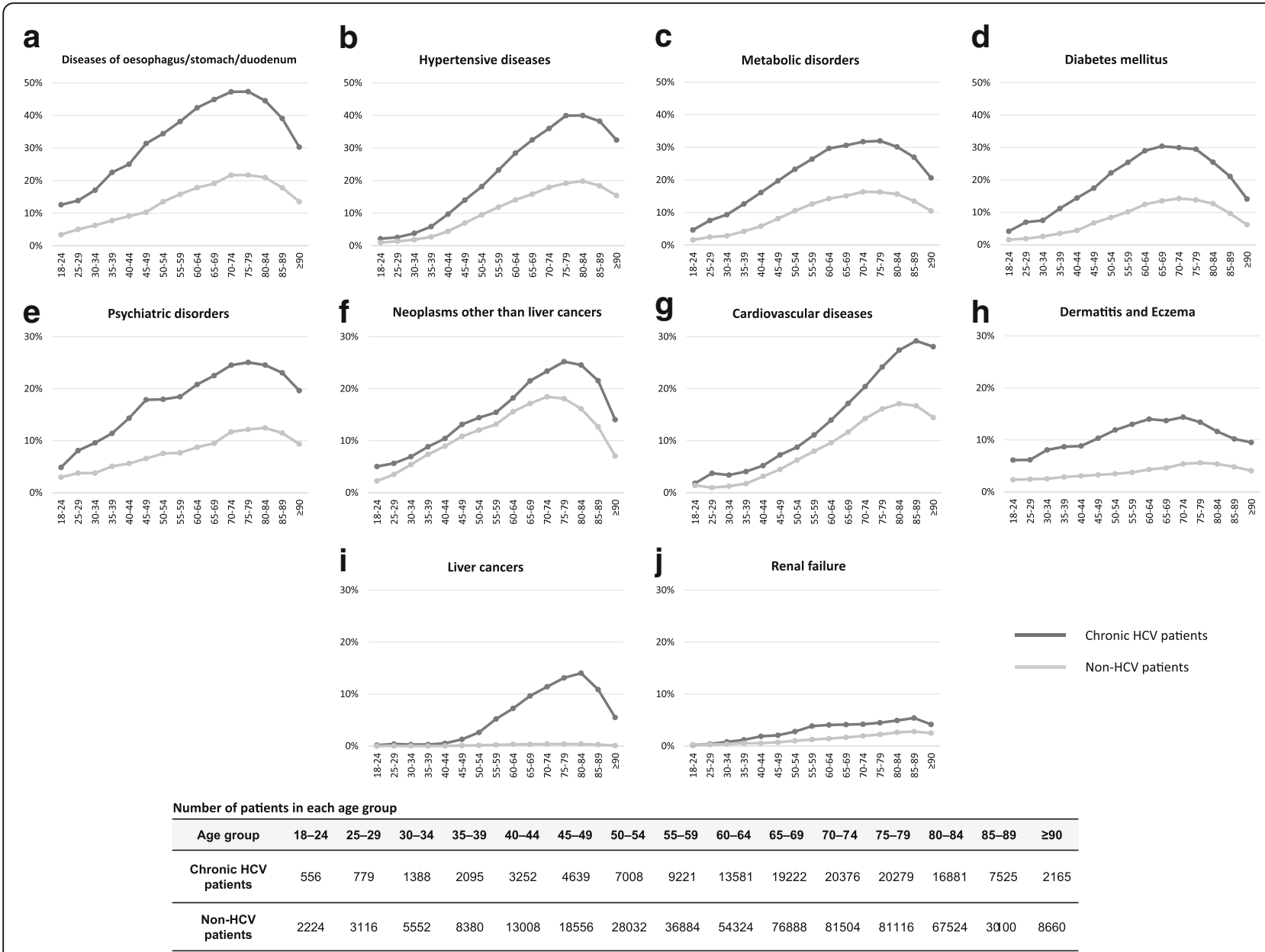

Fig. 2 Prevalence of systemic diseases by age group in chronic HCV patients and non-HCV patients. a diseases of oesophagus, stomach and duodenum; b hypertensive diseases; c metabolic disorders; $\mathbf{d}$ diabetes mellitus; e psychiatric disorders; $\mathbf{f}$ neoplasms other than liver cancers; $\mathbf{g}$ cardiovascular diseases; $\mathbf{h}$ dermatitis and eczema; $\mathbf{i}$ liver cancers; and $\mathbf{j}$ renal failure
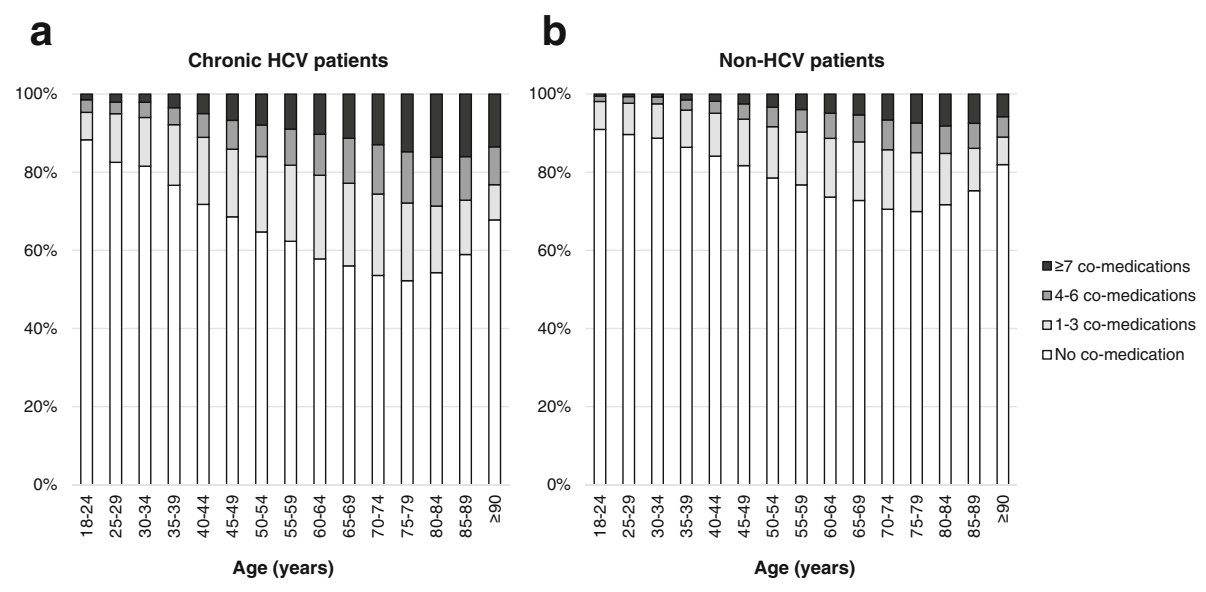

Fig. 3 Proportions of patients with different numbers of co-medications by age group. a chronic HCV patients and $\mathbf{b}$ non-HCV patients 


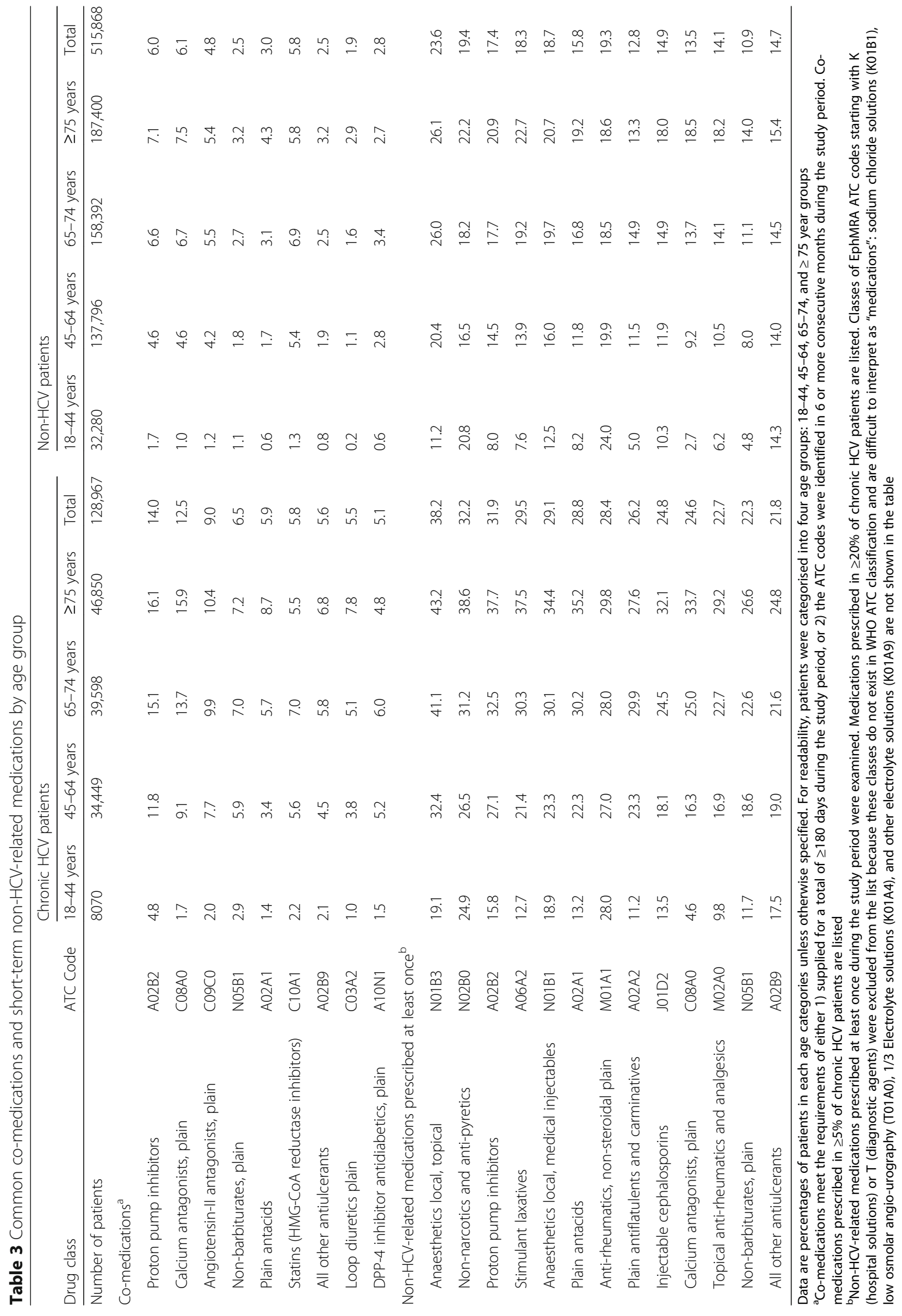


across the age groups in a very similar way in the two groups, although the proportion with no comorbidities was lower from a younger age in the chronic HCV group (see Fig. 1). A similar trend has been described for patients with ongoing HIV infection and it has been hypothesised that this might imply premature aging in those patients, possibly caused by persistent inflammatory and immune changes $[18,19]$. Unfortunately, however, we did not examine whether similar changes occurred in chronic HCV patients.

The most common comorbidities in chronic $\mathrm{HCV}$ patients were diseases of oesophagus, stomach and duodenum (41.7\%), hypertensive diseases (31.4\%), and metabolic disorders (28.2\%). A US study reported similar findings among chronic $\mathrm{HCV}$ patients: gastrointestinal disorders (24.4\%), oesophageal disorders (20.5\%), essential hypertension (32.6\%), and disorders of lipid metabolism (25.9\%) [11]. We also found that all ten systemic diseases were more common in chronic $\mathrm{HCV}$ patients than non-HCV patients, and that the prevalence of most systemic diseases tended to become higher in older chronic $\mathrm{HCV}$ patients. Our findings underscore the importance of age-related comorbidities such as hypertensive diseases, metabolic disorders, cardiovascular diseases and malignancies in older chronic HCV patients.

Chronic HCV patients used more co-medications than non-HCV patients, and more than one in five chronic HCV patients (22.9\%) used at least four co-medications. Although direct comparisons of our results with previous findings are not appropriate because of different study methods, German studies have previously reported that $31-34 \%$ of HCV patients took at least four regular out-patient medications [3, 20]. An Italian study showed that $31.0 \%$ of chronic $\mathrm{HCV}$ patients with liver diseases used at least four co-medications, and estimated that $30-44 \%$ of chronic HCV patients receiving DAAs and using co-medications were at risk of DDIs [21]. The proportion in our study was slightly smaller than reported in these countries, but this may be because of our strict definition of co-medications. The common use of multiple co-medications in our study implies that chronic $\mathrm{HCV}$ patients in Japan may be at similarly high risk of potential DDIs.

The five most common co-medications used by chronic HCV patients were proton pump inhibitors, calcium antagonists, angiotensin-II antagonists, non-barbiturates, and antacids. This is similar to a German study reporting that the five most common co-medications included beta-blockers, proton pump inhibitors, thyroid hormones, angiotensin-II antagonists, and dihydropyridine calcium channel blockers [3]. The common use of gastric acid suppressants and hypertensive agents in our study might be attributed to our finding of a high prevalence of gastric diseases and hypertension in chronic HCV patients in Japan.
Gastric acid suppressants (e.g. proton pump inhibitors, antacids) have potential DDIs with DAAs [20-23]. These medications alter the acid environment, which can result in reduced absorption of certain drugs such as ledipasvir [22, 23]. Calcium antagonists also have potential DDIs with DAAs; plasma concentration of these medications can be increased by the concomitant use of CYP3A inhibitors such as telaprevir and simeprevir [22-24]. In this study, both these co-medications were common, especially in older chronic HCV patients. Although our chronic $\mathrm{HCV}$ population included a large proportion of untreated patients, examination of co-medication profiles in treated patients revealed that proton pump inhibitors and calcium antagonist were commonly prescribed to patients treated with DAAs (13.5 and $13.3 \%$, respectively), roughly corresponding to the results of the overall chronic HCV population [see Table 3 \& Additional file 1: Table S1]. Because of our strict definition of co-medications, our results probably reflect the medications used for chronic conditions, meaning that these medications may be difficult to stop or substitute. To select the optimal DAA treatment for chronic HCV patients, physicians should pay careful attention to the long-term use of these medications in their patients.

Even short-term use of other medications can influence DAA treatment. However, patients may not always inform their physicians about short-term use of medications, probably because they are not aware of the risks for DDIs. This study also examined short-term use of medications, and found that proton pump inhibitors, antacids, and calcium antagonists were used by about 25-30\% of chronic HCV patients. Other classes of medications with potential DDIs with DAAs, such as analgesics, diuretics, and sedatives were also used by many chronic HCV patients [see Additional file 2: Table S2] $[24,25]$. These results reinforce the need for physicians to have an exact knowledge of medication profiles of chronic HCV patients to avoid or manage DDIs. When initiating a DAA treatment, physicians may need to consider appropriate action for the management of DDIs, such as discontinuation, dose change, use of alternative medications, and increased monitoring of patients [23].

This study has several limitations. First, the generalisability of its results may be limited because the hospitals included in the database are only those with advanced medical care capabilities (e.g., acute care hospitals, general hospitals). The chronic HCV patients studied may therefore be "sicker" than other patients such as those treated at clinics. Likewise, the non-HCV patients may have severe medical conditions, which would influence the results. Second, the study has limitations inherent in the use of a pre-existing hospital claims database, such as misclassification owing to incorrectly recorded or missing data. For example, the diagnosis of chronic 
HCV infection was based on the diagnosis record and its accuracy might vary from hospital to hospital. Patients may have received other medications for other comorbidities at different hospitals, but this could not be traced. The lack of data on the time of HCV clearance in patients may have resulted in under- or overestimation of comorbidities. The low prevalence of $\mathrm{HCV}$-related cirrhosis among chronic HCV patients may also be attributed in part to underestimation stemming from limitations of the database (i.e., miscoding, lack of data). However, this may also be explained by the difficulty of correct diagnosis of cirrhosis, which requires biopsy. Whereas patients usually undergo biopsy when they start HCV treatment, most of our chronic HCV patients were untreated, implying that not many patients who were likely to receive a correct diagnosis of $\mathrm{HCV}$-related cirrhosis were included. Third, we set strict definitions to identify the chronic comorbidities and co-medications most likely to have been used to treat chronic conditions, which may have resulted in underestimation of both comorbidities and co-medications because patients may not constantly visit the hospital. Fourth, we examined ten relevant systemic diseases, but these are not comprehensive. Investigation of other extrahepatic manifestations is needed for a more comprehensive understanding of systemic manifestations in chronic $\mathrm{HCV}$ patients in Japan [see Additional file 3: Table S3 for additional data of additional extrahepatic manifestations of chronic HCV infection]. Finally, this study was unable to investigate any causal relationships between the results and chronic HCV infection or DAA treatment because the comorbidities and co-medications were not examined against the timing of diagnosis or treatment. Further studies may shed light on these relationships.

\section{Conclusions}

In the present study in Japan, patients with chronic $\mathrm{HCV}$ had more comorbidities than those without $\mathrm{HCV}$ regardless of age. In particular, older chronic $\mathrm{HCV}$ patients commonly had multiple comorbidities and used more co-medications. The results suggest the difficulty of managing chronic HCV patients in Japan, especially older patients constituting the majority of the HCV patient population in Japan, because of the potential for DDIs. To provide optimal DAA treatment for this older patient population, it is important for physicians to closely monitor their medication profiles and take appropriate action to manage DDIs.

\section{Additional files}

Additional file 1: Table S1. Common co-medications in treated and non-treated chronic HCV patients. Description of data: The proportions of patients who received common co-medications in treated chronic HCV patients (including patients treated with DAAs and patients treated with peginterferon plus ribavirin) and non-treated chronic HCV patients are summarised. (DOCX $17 \mathrm{~kb}$ )

Additional file 2: Table S2. Non-HCV-related medications prescribed at least once during the study period by age group. Description of data: The proportions of patients who received non-HCV-related medications at least once during the study period are summarised by age for both chronic HCV patients and non-HCV patients. (XLSX $184 \mathrm{~kb}$ )

Additional file 3: Table S3. Prevalence of other extrahepatic manifestations of chronic HCV infection. Description of data: Prevalence of additional extrahepatic manifestations that were not included in the analysis of 10 relevant systemic diseases in patients with or without chronic HCV. (DOCX $17 \mathrm{~kb})$

\section{Abbreviations}

ATC codes: The EphMRA Anatomical classification system codes; DAA: Directacting anti-viral agent; DDI: Drug-drug interaction; HBV: Hepatitis B virus; HCV: Hepatitis C virus; ICD-10: The International Statistical Classification of Diseases and Related Health Problems 10th Revision

\section{Acknowledgements}

Medical writing and statistical supports were provided by Clinical Study Support, Inc. The contents of this study were presented at the 27th Annual Conference of APASL in New Delhi, India, on March 14-18, 2018.

\section{Funding}

The study was funded by MSD K.K. MSD K.K. had no role in the data collection, but was involved in the study design, data analysis, and preparation of the manuscript.

\section{Availability of data and materials}

This study used a de-identified data set provided by Medical Data Vision, Co., Ltd. (MDV), a commercial database provider. Sharing the MDV data set online is difficult owing to contractual agreements between MDV and medical facilities. For inquiries about access to the data set used in this study, please contact MDV (website, https://www.mdv.co.jp/; e-mail, ebm_sales@mdv.co.jp).

\section{Authors' contributions}

DJR, JT, GF, and TK contributed to the conception and design of the study. GF contributed to the data analysis, and DJR, JT, GF, and TK contributed to the data interpretation. DJR was involved in drafting of the manuscript, and $D J R, J T, G F$, and TK revised it critically. All authors read and approved the final version of the manuscript.

\section{Ethics approval and consent to participate}

This was an observational study using de-identified medical claims data. Because the Japanese Ethical Guidelines for Medical and Health Research Involving Human Subjects (http://www.mhlw.go.jp/file/06-Seisakujouhou-10600000Daijinkanboukouseikagakuka/0000153339.pdf) do not apply to studies exclusively using de-identified data, we were not obligated to apply for an ethical approval for this study and to obtain informed consent in this study.

\section{Competing interests}

DJR, JT, and GF are employed by MSD K.K. TK has no competing interests to declare on this work.

\section{Publisher's Note}

Springer Nature remains neutral with regard to jurisdictional claims in published maps and institutional affiliations.

\section{Author details}

'Medical Affairs, MSD K.K, Kitanomaru Square, 1-13-12 Kudan-kita, Chiyoda-ku, Tokyo 102-8667, Japan. ${ }^{2}$ Biostatistics and Research Decision Sciences, MSD K.K, Kitanomaru Square, 1-13-12 Kudan-kita, Chiyoda-ku, Tokyo 102-8667, Japan. ${ }^{3}$ The Research Center for Hepatitis and Immunology Department of Liver Disease, National Center for Global Health and Medicine, 1-7-1 Kohnodai, Ichikawa, Chiba 272-8516, Japan. 
Received: 25 October 2017 Accepted: 15 May 2018

Published online: 24 May 2018

\section{References}

1. Toshikuni N. Therapy with direct-acting antiviral agents for hepatitis C-related liver cirrhosis. Gut Liver. 2016; https://doi.org/10.5009/gnl15458.

2. Schinazi $R$, Halfon $P$, Marcellin $P$, Asselah T. HCV direct-acting antiviral agents: the best interferon-free combinations. Liver Int. 2014;34:69-78.

3. Maasoumy B, Port K, Calle Serrano B, Markova AA, Sollik L, Manns MP, et al. The clinical significance of drug-drug interactions in the era of direct-acting anti-viral agents against chronic hepatitis C. Aliment Pharmacol Ther. 2013;38:1365-72.

4. Zampino R, Marrone A, Restivo L, Guerrera B, Sellitto A, Rinaldi L, et al. Chronic HCV infection and inflammation: clinical impact on hepatic and extra-hepatic manifestations. World J Hepatol. 2013;5:528-40.

5. Tang L, Marcell L, Kottilil S. Systemic manifestations of hepatitis C infection. Infect Agents Cancer. 2016;11:29.

6. Shepard CW, Finelli L, Alter MJ. Global epidemiology of hepatitis C virus infection. Lancet Infect Dis. 2005;5:558-67.

7. Chen SL, Morgan TR. The natural history of hepatitis C virus (HCV) infection. Int J Med Sci. 2006;3:47-52.

8. Lee MH, Yang HI, Lu SN, Jen CL, You SL, Wang LY, et al. Chronic hepatitis $C$ virus infection increases mortality from hepatic and extrahepatic diseases: a community-based long-term prospective study. J Infect Dis. 2012;206:469-77.

9. Lauffenburger JC, Mayer CL, Hawke RL, Brouwer KL, Fried MW, Farley JF. Medication use and medical comorbidity in patients with chronic hepatitis C from a US commercial claims database: high utilization of drugs with interaction potential. Eur J Gastroenterol Hepatol. 2014;26:1073-82.

10. Vespasiani-Gentilucci U, Galati G, Gallo P, De Vincentis A, Riva E, Picardi A. Hepatitis $C$ treatment in the elderly: new possibilities and controversies towards interferon-free regimens. World J Gastroenterol. 2015;21:7412-26.

11. Louie KS, St Laurent S, Forssen UM, Mundy LM, Pimenta JM. The high comorbidity burden of the hepatitis $C$ virus infected population in the United States. BMC Infect Dis. 2012;12:86.

12. Alter MJ. Epidemiology of hepatitis C virus infection. World J Gastroenterol. 2007;13:2436-41.

13. Kamae I, Kumada H, Kobayashi M, Ward T, Webster S, Yuan Y, et al. Epidemiology, treatment and health economics of hepatitis $C$ in Japan (Review). Kanzo. 2014;55:589-603. Japanese

14. Karino Y. Innovation in hepatitis C treatment. J Japan Assoc Rural Med. 2016;65:129-35. Japanese

15. Chung $H$, Ueda $T$, Kudo M. Changing trends in hepatitis $C$ infection over the past 50 years in Japan. Intervirology. 2010;53:39-43.

16. International Statistical Classification of Diseases and Related Health Problems 10th Revision. http://apps.who.int/classifications/icd10/browse/ 2016/en. Accessed 24 May 2017.

17. EphMRA. EphMRA Anatomical Classification Guidelines. https://www. ephmra.org/media/1090/atcguidelines2016final.pdf. Accessed 24 May 2017.

18. Guaraldi G, Orlando G, Zona S, Menozzi M, Carli F, Garlassi E, et al. Premature age-related comorbidities among HIV-infected persons compared with the general population. Clin Infect Dis. 2011;53:1120-6.

19. Schouten J, Wit FW, Stolte IG, Kootstra NA, van der Valk M, Geerlings SE, et al. Cross-sectional comparison of the prevalence of age-associated comorbidities and their risk factors between HIV-infected and uninfected individuals: the AGEhIV cohort study. Clin Infect Dis. 2014:59:1787-97.

20. Höner Zu Siederdissen C, Maasoumy B, Marra F, Deterding K, Port K, Manns MP, et al. Drug-drug interactions with novel all oral interferon-free antiviral agents in a large real-world cohort. Clin Infect Dis. 2016;62:561-7.

21. Kondili LA, Gaeta GB, leluzzi D, Zignego AL, Monti M, Gori A, et al. Real-life data on potential drug-drug interactions in patients with chronic hepatitis $C$ viral infection undergoing antiviral therapy with interferon-free DAAs in the PITER Cohort Study. PLoS One. 2017;12:e0172159.

22. Dick TB, Lindberg LS, Ramirez DD, Charlton MR. A clinician's guide to drugdrug interactions with direct-acting antiviral agents for the treatment of hepatitis C viral infection. Hepatology. 2016;63:634-43.

23. Langness JA, Nguyen M, Wieland A, Everson GT, Kiser JJ. Optimizing hepatitis $C$ virus treatment through pharmacist interventions: identification and management of drug-drug interactions. World J Gastroenterol. 2017;23: $1618-26$.
24. Burger D, Back D, Buggisch P, Buti M, Craxí A, Foster G, et al. Clinical management of drug-drug interactions in HCV therapy: challenges and solutions. J Hepatol. 2013;58:792-800.

25. Badri PS, King JR, Polepally AR, McGovern BH, Dutta S, Menon RM. Dosing recommendations for concomitant medications during 3D anti-HCV therapy. Clin Pharmacokinet. 2016:55:275-95.

\section{Ready to submit your research? Choose BMC and benefit from:}

- fast, convenient online submission

- thorough peer review by experienced researchers in your field

- rapid publication on acceptance

- support for research data, including large and complex data types

- gold Open Access which fosters wider collaboration and increased citations

- maximum visibility for your research: over $100 \mathrm{M}$ website views per year

At BMC, research is always in progress.

Learn more biomedcentral.com/submissions 